\title{
Uses of Polymeric Nanoparticles Derived from Plant Gum ${ }^{\dagger}$
}

\author{
Ummu Bisyarah Binti Kassim ${ }^{1}$, Akasha Arif ${ }^{1, *}$ \\ 1 School of Bioscience, Faculty of Medicine, Bioscience and Nursing, MAHSA University, Jenjarom, Selangor, Malaysia \\ * Correspondence: akashaarif29@gmail.com; \\ $\uparrow$ Presented at International e-Conference on Bioengineering for Health and Environment (ICBHE 2020)
}

Received: 5.07.2020; Revised: 10.07.2020; Accepted: 12.07.2020; Published: 15.07.2020

\begin{abstract}
Nanocarriers can be used to carry different types of materials, for instance, drugs, and play a major role in therapy. In this study, gum was collected and subjected to water extract, used for various bioactive studies. It was purified and characterized. The purified gum was used for nanocarrier synthesis, where sodium trimetaphosphate (STMP) was utilized to synthesize nanocarriers. The gum extract was observed to have antioxidant and antibacterial properties. UV-Vis, SEM, AFM, zeta potential, and FTIR analysis were performed. By these analyses, the nanocarriers were found to be stable for the delivery of the drug. The best antibacterial activity was observed in the loaded nanocarriers.
\end{abstract}

Keywords: Nanocarriers; gum extract; antibacterial; antioxidant; biopolymer.

(C) 2020 by the authors. This article is an open-access article distributed under the terms and conditions of the Creative Commons Attribution (CC BY) license (https://creativecommons.org/licenses/by/4.0/).

\section{Funding}

This research received no external funding.

\section{Acknowledgments}

This research has no acknowledgment.

\section{Conflicts of Interest}

The authors declare no conflict of interest. 